\title{
SINIR DEĞERLER ARASINDA KALAN EVSEL ATIKSU NUMUNE ANALİZİ SONUCUNUN AŞIRI ÖĞRENME MAKİNELERİ İLE SINIFLANDIRILMASI
}

\author{
${ }^{*}$ Burhan BARAN
}

Çevre ve Şehircilik İl Müdürlüğü, Malatya, Türkiye

\begin{tabular}{l} 
Anahtar Kelimeler \\
\hline Atıksu, \\
Numune, \\
Analiz, \\
Așırı öğrenme makineleri.
\end{tabular}

Aşırı öğrenme makineleri. \begin{abstract}
Öz
Bu çalışmada atıksu arıtma tesislerinden arıtıldıktan sonra alıcı deşarj ortamlarına verilen atıksuyun temizlik derecesinin Așırı Öğrenme Makineleri (AÖM) algoritması ile tahmin edilmesi amaçlanmıştır. Bu amaçla, Su Kirliliği Kontrolü Yönetmeliği (SKKY) Tablo 21.1'de belirtilen parametreler için 2 saatlik kompozit numune sınır değerleri içerisinde kalan temiz suyun sınıflandırılması yapılmıştır. Öncelikle bu parametrelere ait alt ve üst sınır değerleri arasındaki tüm değerler 0 ile 1 arasında normalize edilmiştir. Ardından, parametrelerin en düşük ve en yüksek sonuç değerlerinin \% 0 ile \% 100 arasındaki yüzdelik oranlara sahip olduğu kabul edilmiştir. Daha sonra, bu yüzdelik oranlar eşit şekilde 1 ile 4 arasında matematiksel olarak sınıflandırılmıştır. Buna göre 1. sınıf çok temiz suyu ifade ederken, 4. sınıf az temiz suyu ifade etmektedir. Bu doğrultuda, AÖM ile sınıflandırma çalışması için birbirinden farklı 50 adet normal ölçüm sonucuna karşılık gelen normalize ve matematiksel sınıflandırma değerleri elde edilmiştir. Normalize değerler AÖM'nin eğitimi için giriş verisi olarak, matematiksel sınıflandırma değerleri ise çıkış verisi olarak kullanılmıştır. Buna karşılık bu parametreler için rastgele seçilen ve sınır değerler içerisindeki 10 adet ölçüm sonucuna karşılık gelen normalize değerler ise AÖM'nin test işleminde giriş verisi olarak kullanılmıştır. Son olarak, elde edilen tahmini ve matematiksel sınıflandırma sonuçları karşılaştırılarak AÖM'nin başarısı ölçülmüştür.
\end{abstract}

\section{CLASSIFICATION FOR RESULT OF HOUSEHOLD WASTEWATER SAMPLE ANALYSIS BETWEEN LIMIT VALUES BY EXTREME LEARNING MACHINES}

\section{Keywords}

Waste water,

Sample,

Analysis,

Extreme learning machine.

\begin{abstract}
In this study, it is aimed to estimate degree of cleanliness of wastewater given to receiving discharge environment after purification from wastewater treatment plants by Extreme Learning Machines (ELM) algorithm. Parameters that specified in Table 21.1 of Water Pollution Control Regulation were taken into account. For this purpose, clean water remaining within 2 hours composite sample limit values was classified. First, all values between lower and upper limit values of these parameters were normalized between 0 and 1 . Subsequently, it was assumed that minimum and maximum result values of parameters were between $0 \%$ and $100 \%$. After that, these percentage ratios were classified mathematically between 1 and 4 in equal proportions. According to this, the 1 st class refers to very clean water, while the 4 th class refers to less clean water. In this respect, normalized and mathematical classification values corresponding to 50 normal measurement results were obtained for classification study with ELM. Normalized values were used as input data for training of ELM and mathematical classification values were used as output data. On the other hand, normalized values corresponding to 10 measurement results within limit values selected randomly for these parameters were used as input data in test procedure of ELM. Finally, success of ELM was measured by comparing estimated and mathematical classification results.
\end{abstract}

Alıntı / Cite

Baran, B., (2019). Sınır Değerler Arasında Kalan Evsel Atıksu Numune Analizi Sonucunun Așırı Öğrenme Makineleri İle Sınıflandırılması, Mühendislik Bilimleri ve Tasarım Dergisi, 7(1), 18 - 25.

\footnotetext{
* ilgili yazar / Corresponding author: burhanbaran@gmail.com
} 


\begin{tabular}{l|l|l}
\hline Yazar Kimliği / Author ID (ORCID Number) & \multicolumn{3}{|l}{ Makale Süreci / Article Process } \\
\hline B. Baran, 0000-0001-6394-412X & Başvuru Tarihi / Submission Date & 24.09 .2018 \\
& Revizyon Tarihi / Revision Date & 10.11 .2018 \\
& Kabul Tarihi / Accepted Date & 10.11 .2018 \\
& Yayım Tarihi / Published Date & 25.03 .2019 \\
\hline
\end{tabular}

\section{Giriş}

Hızlı nüfus artışı, ekonomik gelişim ve yaşam standartlarındaki yükseliş birçok olumsuzluğa yol açtığı gibi su kaynaklarının kirlenmesine de sebep olmaktadır. Temiz su kaynaklarından temin edilen su, insani ihtiyaçlar için kullanıldıktan sonra evsel atıksu olarak tahliye edilmektedir. Tahliye edilen bu atıksu miktarlarının oluşumu kentlerin nüfusuna ve içme suyu kaynaklarına bağlı olarak değişmektedir. Temiz suyun atıksu haline dönüşmesiyle birlikte fiziksel, kimyasal ve bakteriyolojik özellikleri de kaybolmaktadır. Kaybedilen bu özelliklerin tekrar kazandırılabilmesi için atıksuyun arıtıldıktan sonra alıcı ortama deşarj edilmesi gerekmektedir. Arıtıldıktan sonra deşarj edilen atıksu karakterizasyonu bölgeden bölgeye farklılık gösterebilmektedir. Atıksuyun kirliliği ifade edilirken tüm parametrelerin takibi pratikte mümkün olmadığı gibi atıksuyun çok fazla kirlilik parametresine sahip olmasından dolayı kirlilik oranının formül ile ifade edilmesi de zordur. Ayrıca, "Su Kirliliği Kontrolü Yönetmeliği (SKKY), Tablo 21: Evsel Nitelikli Atık Suların Alıcı Ortama Deşarj Standartları" ana başlığı altındaki "Evsel Nitelikli Atıksular" başlıklı tüm sektörlerde sadece dört parametreye ait sınır değerler belirlenmiştir. Buna bağlı olarak bu çalışma kapsamındaki kirlilik tahminlerinde Biyokimyasal Oksijen İhtiyacı (BOİ5), Kimyasal Oksijen İhtiyacı (KOI), Askıda Katı Madde (AKM) ve pH dikkate alınmıștır (Tanyol ve Gülșad, 2013; Erdoğan v.d., 2005).

$\mathrm{BOI}_{5}$ suda mikro organizmalar tarafından ayrıştırılabilen organik maddelerin miktarını belirlemede kullanılan bir parametre olup, bu maddelerin ayrıștırılabilmesi için ihtiyaç duyulan oksijen miktarını, KOİ kimyasal olarak oksitlenebilen organik maddelerin oksijen ihtiyacını, AKM su numunelerinin standart filtre kağıdından süzülmesi ve filtrenin kurutulması sonucunda elde edilen kalıntıları, $\mathrm{pH}$ ise suyun asidik veya bazik durumunu ifade etmektedir (Sinan, 2010; Bingül ve Altıkat, 2017). Ayrica, alıcı ortam terimi arıtma tesisinden çıkan atıksuyun verildiği su ortamını, kompozit numune terimi ise atıksu analizi için belirli zaman aralıklarında alınan karıșık numuneyi ifade etmektedir.

Bu çalışmada, SKKY Yönetmeliği Tablo 21.1'deki BOİ5, KOİ, AKM ve pH parametreleri ve 2 saatlik kompozit numune sınır değerleri dikkate alınarak elde edilen atıksu numune sonuçlarının temizlik derecesi tahmini yapılmıștır. $\mathrm{Bu}$ parametrelere ait sınır değerler arasında kalan tüm değerler AÖM algoritması kullanılarak sınıflandırılmıştır. Parametrelerin en düşük sonuç değerlerinin \% 0 , en yüksek sonuç değerlerinin ise \% 100 olduğu kabul edilmiştir. \% 0,00 - \% 24,99 aralığı 1. sınıf, \% 25,00 - \% 49,99 aralığ 2. sınıf, \% 50,00 - \% 74,99 aralığı 3. sınıf, \% 75,00 - \% 100,00 aralığı ise 4 . sınıf olacak şekilde matematiksel olarak sınıflandırılmıştır. Buna göre 1. sınıf çok temiz suyu ifade ederken, 4. sinıf az temiz suyu ifade etmektedir. Bu doğrultuda, AÖM ile sinıflandırma çalışması için birbirinden farklı 50 adet normal ölçüm sonucuna karşılık gelen normalize ve matematiksel sınıflandırma değerleri elde edilmiştir. Normalize değerler AÖM'nin eğitimi için giriş verisi olarak, matematiksel sınıflandırma değerleri ise çıkış verisi olarak kullanılmıştır. Buna karşılık bu parametreler için rastgele seçilen ve sınır değerler arasında olan 10 adet sonuca karşılık gelen normalize değerler ise AÖM'nin test işleminde giriş verisi olarak kullanılmıştır. Son olarak, elde edilen tahmini ve matematiksel sinıflandırma sonuçları karşılaştırılmıștır.

\section{Bilimsel Yazın Taraması}

R.K. Sinan tarafından yapılan çalışmada, evsel nitelikli bir atıksu arıtma tesisindeki hem ön arıtma hem de biyolojik arıtma ara aşamaları için, bu aşamalara ait işletim parametrelerinin giriş değerlerinin dikkate alınması suretiyle tahmini çıkış değerlerinin Yapay Sinir Ağları (YSA) modeli ile tespiti üzerine bir çalışma yapılmıştır. KASKI Atıksu Arıtma Tesisi işletme veri tabanına ait 238 adet ölçüm sonucunun 180 tanesi YSA'nın eğitiminde, 58 tanesi de YSA'nın test edilmesi amacıyla kullanılmıştır. İki YSA modeli seçilmiştir. YSA-1 modelinde, aktivasyon fonksiyonu olarak tansig, logsig, radbas ve purelin fonksiyonları kullanılmıștır. Eğitme ve test süreci sonunda, YSA-1 modeli için genellemeye ulaşan en uygun yapay sinir ağının, purelin-purelin 8 düğüm sayılı yapı; YSA-2 modeli için ise genellemeye ulaşan en uygun yapay sinir ağının, purelin-purelin 13 düğüm sayılı yapı olduğu tespit edilmiştir (Sinan, 2010).

Francesco Granata v.d. tarafından yapılan çalışmada, drenaj havzasının drenaj alanı, yerleşim alanı yüzdesi, kurumsal alanın yüzdesi, ticari alan yüzdesi, sanayi alanının yüzdesi, açı alan yüzdesi, otoban yüzdesi, geçirimsiz alan yüzdesi, yağış yüzdesi derinlik ve akış özelliklerine dayanarak atıksu kalite göstergelerinin tahmini için bir yöntem geliştirilmesi amaçlanmıştır. Yapay zekâ üzerine yapılan çalışmalardan türeyen Destek Vektör Regresyon ve Regresyon Ağaçları modelleri karșılaștırılmıștır. Çalıșma sonucunda, her iki modelin de sağlamlık, güvenilirlik ve yüksek genelleme kabiliyeti gösterdiği, Destek Vektör 
Regresyonunun AKM ve KOİ'yi öngörmede Regresyon Ağacından daha iyi bir performans gösterdiği gözlemlenmiştir. BOİ ile ilgili olarak ise iki model karşılaştırılabilir bir performans göstermiştir (Granata v.d., 2017).

Maged M. Hamed ve arkadașları tarafindan yapılan çalışmada bir atıksu arıtma tesisinin performansını tahmin etmek için bir YSA modeli geliştirilmiştir. Bu çalışmada kullanılan veriler, Mısır'ın Büyük Kahire bölgesinde, ortalama 1 milyon $\mathrm{m}^{3}$ /gün akış hızına sahip bir arıtma tesisinden elde edilmiștir. BOİ ve AKM değerleri günlük olarak 10 ay boyunca arıtma işleminin çeşitli aşamalarında kaydedilmiştir. Bitki atıklarında BOİ ve AKM değerlerinin tahmini için iki YSA bazlımodel sunulmuştur. Nöral ağ modellerinin uygun mimarisi, modellerin eğitim ve testinin birkaç adımı ile belirlenmiştir. Çalışmanın sonucunda YSA tabanlı modelin atıksu arıtma tesislerinin performansını tahmin etmede etkili olduğu kanaatine varılmıștır (Hamed v.d., 2004).

Rene v.d. tarafından yapılan çalışmada regresyon analizi ve yapay sinir ağları kullanılarak çeşitli su kalitesi parametreleri arasındaki ilişkilerin haritalandırılması amaçlanmıştır. Farklı YSA modelleri geliștirilmiștir. 1500 eğitim verili ve 8 gizli nörona sahip YSA modeli KOİ için iyi sonuçlar verirken, 5000 eğitim verili ve 7 gizli nörona sahip YSA modeli BOİ için iyi sonuçlar göstermiștir. Ayrıca, hem BOİ hem de KOİ'yi tahmin etmek için ayrı bir YSA modeli geliştirilmiştir. Sonuç olarak, bu modellerin hepsi test verileriyle test edilmiştir ve testler sonucunda geliştirilen YSA modellerinin rafineri atıksuları için yüksek dereceli güven seviyesi ile uygulanabileceği sonucuna ulașılmıștır (Rene v.d., 2008).

$\mathrm{Bu}$ çalışmada ise, evsel atıksu arıtma tesislerinden arıtıldıktan sonra alıcı ortamlara verilen atıksuya ait numune sonuçlarının sınır değerler içerisinde çıkan sınıflandırma sonuçları ile matematiksel sınıflandırma sonuçları karşılaştırılarak AÖM'nin başarısı ölçülmüștür. Bu açıdan temiz çıkan atıksu numune sonuçlarının sınıflandırılması üzerine yapılan bu çalışmanın literatüre katkı sağlayacağı düşünülmektedir.

\section{Materyal ve Yöntem}

\subsection{Alıcı Ortama Deşarj Standartları}

SKKY Tablo 21.1'de belirtilen BOİ, KOİ, AKM ve pH parametreleri için 2 saatlik numunelere ait üst sınır değerleri Tablo 1'deki gibidir.
Tablo 1. Evsel Nitelikli Atık Suların Alıcı Ortama Deșarj Standartları (SKKY, 2004)

\begin{tabular}{|c|c|c|}
\hline PARAMETRE & BİRIM & $\begin{array}{c}\text { KOMPOZIT } \\
\text { NUMUNE } \\
\text { 2 SAATLIK }\end{array}$ \\
\hline $\begin{array}{c}\text { BIYOKIMYASAL OKSIJEN } \\
\text { IHTIYACI (BOİ) }\end{array}$ & $(\mathrm{mg} / \mathrm{L})$ & 50 \\
\hline $\begin{array}{c}\text { KIMYASAL OKSIJEN } \\
\text { IHTTIYACI (KOI) }\end{array}$ & $(\mathrm{mg} / \mathrm{L})$ & 180 \\
\hline $\begin{array}{c}\text { ASKIDA KATI MADDE } \\
\text { (AKM) }\end{array}$ & $(\mathrm{mg} / \mathrm{L})$ & 70 \\
\hline $\mathbf{p H}$ & - & $6-9$ \\
\hline
\end{tabular}

\subsection{Aşırı Öğrenme Makineleri}

Bu bölümde öncelikle Huang ve arkadaşları tarafından geliștirilen aşırı öğrenme makinesi anlatılıp, ardından girilen eğitim verilerine karşılık, herhangi ölçülen numune sonuçlarına sahip yukarıdaki parametrelerin AÖM ile nasıl sınıflandırılacağı üzerine bir çalışma yapılmıştır.

İstatistiksel ve matematiksel yöntemler kullanarak hazır verilerden çıkarımlar yapan, bu çıkarımlar aracılığ kullanılan yöntem Makine Öğrenmesidir. AÖM ise tek bir gizli katmana sahip ileri beslemeli yapay sinir ağlarını eğitmek için önerilmiş bir yöntemdir. AÖM'nde çıkıș ağırlıkları analitik olarak hesaplanırken, giriș ağırlıkları rastgele hesaplanır. Çıkış katmanında doğrusal fonksiyon kullanılırken, gizli katmanda sigmoidal, sine ve hard-limitin gibi aktivasyon fonksiyonları kullanılmaktadır (Baran, 2017).

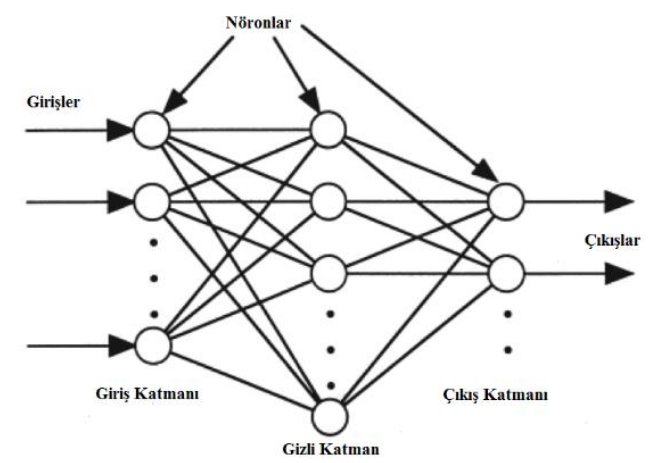

Şekil 1. İleri beslemeli Yapay Sinir Ağı(Baran, 2017).

Geleneksel ileri beslemeli yapay sinir ağlarında eşik değerleri ve ağırlıklar gibi parametreler gradyen bazlı öğrenme algoritmaları aracılığıyla güncellenmek zorundadır. Yine de iyi bir sonuç elde edebilmek için gereken öğrenme süreci zaman alabilmektedir. Hata lokal bir noktaya takılabilmektedir. Ayrıca, tek gizli katmanlı ileri beslemeli bir ağda giriș-çıkıș ağırlıkları ve eşik değerleri ağın performansını etkilememektedir. Şekil 1'de tek gizli katmanlı ileri beslemeli bir yapay sinir ağı gösterilmiştir (Baran, 2017).

Nöron ağının hedefi $\mathrm{f}: \mathrm{X} \rightarrow$ Y şeklinde olan fonksiyonu bulmaktır. $N$ gizli düğüme sahip tek katmanlı ileri 
beslemeli nöron ağı denklem 1'deki gibi tanımlanmıştır (Çatak, 2015).

$$
\left.f_{N}(x)=\sum_{i=1}^{N} B_{i}, G\left(a_{i}, b_{i}, x\right), x \in R, a_{i} \in R\right)
$$

Burada $a_{i}$, ve $b_{i}$, öğrenme parametresi, $B_{i}$, ise $i$. gizli düğümün ağırlığıdır. Genelleștirilmiş tek katmana sahip ileri besleme bir ağ için AÖM'nin çıtı fonksiyonu ise denklem 2'deki gibidir.

$\left.f_{N}(x)=\sum_{i=1}^{N} B_{i} G\left(a_{i}, b_{i}, \mathrm{x}\right)=\beta \mathrm{x} h(x)\right)$

\section{3. Önerilen Yöntem}

$\mathrm{Bu}$ çalışmada atıksu arıtma tesislerinden arıtıldıktan sonra dereye, baraja v.b. ortamlara deşarj edilen atıksuya SKKY Tablo 21.1'de belirtilen BOİ, KOİ, AKM ve $\mathrm{pH}$ parametrelerine göre elde edilen 2 saatlik kompozit numune sonuçları için temizlilik sınıflandırılması yapılmıştır. Sınıflandırma ile elde edilen sonuçlara karşılık gelen yüzdelik oranlar belirlenmiştir. Ayrıca, bu parametrelerin sınır değerleri arasındaki 50 adet sınıflandırma değeri AÖM'nin giriş verisi olarak kullanılmıştır. Buna karşılık bu parametrelere ait herhangi girilen 10 adet parametre değerine ait sonucun AÖM aracılığ ile tahmini yapılmıștır.

Yapay sinir ağların eğitimi, ham verilere uygulandığında çok yavaş olabilir. $\mathrm{Bu}$ sebeple normalize edilmiş veriler ile çalışılması daha hızlı sonuç elde edilmesine olanak sağlamaktadır. Bu amaçla çalışmada kullanılan dört parametreye ait alt ve üst sınır değerleri arasındaki tüm değerler 0 ile 1 değerleri arasına normalize edilmiştir.

$\mathrm{Bu}$ parametreler için normalizasyon işlemleri denklem 3, 4, 5, 6 ve 7 kullanılarak gerçekleştirilmiştir.

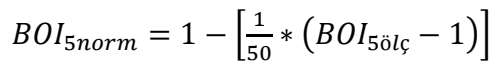

$$
\begin{aligned}
& K O I_{\text {norm }}=1-\left[\frac{1}{180} *\left(K O I_{\text {ölç }}-1\right)\right] \\
& A K M_{\text {norm }}=1-\left[\frac{1}{70} *\left(A K M_{\text {ölç }}-1\right)\right] \\
& p H(6-7)_{\text {norm }}=1-\left[\frac{10}{11} *\left(7-p H_{\ddot{o ̈ l c}}\right)\right] \\
& p H(7-9)_{n o r m}=1-\left[\frac{10}{21} *\left(p H_{\ddot{o ̈ l c ̧}}-7\right)\right]
\end{aligned}
$$

Buna göre ölçülen değerlere karşılık gelen normalize değerler Tablo 2-5'teki gibi elde edilmiştir.
Tablo 2. BOİ ${ }_{5}$ için ölçülen ve atanan normalize değerler

\begin{tabular}{|c|c|}
\hline BOİ $_{\mathbf{5}}$ & Normalize Değeri \\
\hline 1 & 1 \\
\hline 2 & 0,98 \\
\hline 3 & 0,96 \\
\hline 4 & 0,94 \\
\hline$\cdot$ & $\cdot$ \\
\hline$\cdot$ & $\cdot$ \\
\hline 47 & 0,08 \\
\hline 48 & 0,06 \\
\hline 49 & 0,04 \\
\hline 50 & 0,02 \\
\hline
\end{tabular}

Temiz çıkan numunedeki BOİ 5 için en iyi değer 1 , en kötü değer 50'dir. Denklem 3 kullanılarak en iyi değer olan 1 değeri 1'e, en kötü değer olan 50 değeri ise 0,02'ye atanmıştır. Böylece temiz numunedeki BOİ değerleri denklem 3 aracılığıyla 0 ile 1 arasına normalize edilmiştir.

Tablo 3. KOİ için ölçülen ve atanan normalize değerler

\begin{tabular}{|c|c|}
\hline Koi & Normalize Değeri \\
\hline 1 & 1 \\
\hline 2 & 0,99444 \\
\hline 3 & 0,98888 \\
\hline 4 & 0,98332 \\
\hline$\cdot$ & $\cdot$ \\
\hline$\cdot$ & $\cdot$ \\
\hline 177 & 0,02144 \\
\hline 178 & 0,01588 \\
\hline 179 & 0,01032 \\
\hline 180 & 0,00476 \\
\hline
\end{tabular}

Temiz çıkan numunedeki KOİ için en temiz değer 1, en kirli değer 180'dir. Denklem 4 kullanılarak en temiz değer olan 1 değeri 1'e, en kirli değer olan 180 değeri ise 0,0476 'ya sabitlenerek temiz numunedeki KOI değerleri 0 ile 1 arasına normalize edilmiştir.

Temiz çıkan numunedeki AKM için en iyi değer 1, en kötü değer 70'tir. Denklem 5 kullanılarak en iyi değer olan 1 değeri 1'e, en kötü değer olan 70 değeri ise 0,0133'e atanmıştır. Böylece temiz numunedeki AKM değerleri denklem 5 vasıtasıyla 0 ile 1 arasına normalize edilmiştir.

Tablo 4. AKM için ölçülen ve atanan normalize değerler

\begin{tabular}{|c|c|}
\hline AKM & Normalize Değeri \\
\hline 1 & 1 \\
\hline 2 & 0,9857 \\
\hline 3 & 0,9714 \\
\hline 4 & 0,9571 \\
\hline$\cdot$ & $\cdot$ \\
\hline$\cdot$ & $\cdot$ \\
\hline 67 & 0,0562 \\
\hline 68 & 0,0419 \\
\hline 69 & 0,0276 \\
\hline 70 & 0,0133 \\
\hline
\end{tabular}


pH parametresi 6-9 arasında 31 değere bölünmüştür. pH en iyi değerini 7,0 da aldığı için 7,0 değeri 1 değeri ile normalize edilmiștir. 7,0 değerinden 6,0 değerine doğru ve 7,0 değerinden 9,0 değerine doğru ise $\mathrm{pH}$ parametresinin kalitesi düşeceğinden sıfıra yakınsanacak değerlerdeki düşüş oranıyla küçültülmüștür. Bu küçültme işlemi denklem 6 ve denklem 7 kullanılarak gerçekleştirilmiştir. 6,0 değeri 0 'dan bir önceki değer olan 0,091 değerine, 9,0 değeri ise 0 'dan bir önceki değer olan 0,0480 değerine sabitlenmiştir.

Tablo 5. pH için ölçülen ve atanan normalize değerler

\begin{tabular}{|c|c|}
\hline $\mathbf{p H}$ & Normalize Değeri \\
\hline 6,0 & 0,0910 \\
\hline 6,1 & 0,1819 \\
\hline 6,2 & 0,2728 \\
\hline$\cdot$ & $\cdot$ \\
\hline 7,0 & 1 \\
\hline$\cdot$ & $\cdot$ \\
\hline 8,7 & 0,1908 \\
\hline 8,8 & 0,1432 \\
\hline 8,9 & 0,0956 \\
\hline 9,0 & 0,0480 \\
\hline
\end{tabular}

\subsection{AÖM İçin Eğitim Verilerinin Olușturulması}

Eğitim amaçlı veri setinin oluşturulması için BO $\dot{I}_{5}$, KOİ, AKM ve $\mathrm{pH}$ parametrelerine ait 50 farklı sonuç değerin önce yüzdelik değeri belirlenmiștir. Ardından AÖM ile karşılaştırma yapılabilmesi için bu yüzdelik değere karşılık gelen kirlilik sınıfı belirlenmiştir. Kirlilik yüzdesinin belirlenmesi için denklem 8 kullanılmıştır.

$\operatorname{Kirlilik}(\%)=100-\left\{\left[\frac{\mathrm{BO}_{5}+\mathrm{KO}+\mathrm{I}+\mathrm{AKM}+\mathrm{pH}}{4}\right] * 100\right\}$

Daha sonra elde edilen yüzdelik oranlar eşit şekilde 1 ile 4 arasında matematiksel olarak sınıflandırılmıștır.

Tablo 6. Kirliliğin sınıflandırılması

\begin{tabular}{|c|c|c|}
\hline \multicolumn{3}{|c|}{ Kirliliğin Sınıflandırılması } \\
\hline \% Aralığı & Sinıfi & \multirow{5}{*}{$\begin{array}{l}\text { Çok Temiz } \\
\text { Az Temiz }\end{array}$} \\
\hline$\% 0,00-\% 24,99$ & 1 & \\
\hline$\% 25,00-\% 49,99$ & 2 & \\
\hline$\% 50,00-\% 74,99$ & 3 & \\
\hline$\% 75,00-\% 100,00$ & 4 & \\
\hline
\end{tabular}

Tablo 6, denklem 8 kullanılarak BOİ, KOİ, AKM ve pH parametrelerine karşıllk gelen ve matematiksel olarak elde edilen yüzdelik değerler için belirlenen \% aralığını ve bu aralıklara denk gelen sınıf değerlerini göstermektedir. 1. sınıftan 4. sınıfa doğru kirliliğin arttığı kabul edilmiştir. 1. sınıf çok temiz suyu ifade ederken, 4. sinif az temiz suyu ifade etmektedir.
Tablo 7. BOİ5, KOİ, AKM ve pH ölçülen değer, atanan değer, kirlilik yüzdesi ve sınıfı

\begin{tabular}{|c|c|c|c|c|c|c|c|c|c|}
\hline \multicolumn{2}{|c|}{ вої } & \multicolumn{2}{|c|}{ коі } & \multicolumn{2}{|c|}{ AKM } & \multicolumn{2}{|c|}{ pH } & \multirow{2}{*}{$\begin{array}{l}\text { K.Y. } \\
\text { (\%) }\end{array}$} & \multirow{2}{*}{$\begin{array}{l}\mathrm{M} \\
\mathrm{s}\end{array}$} \\
\hline ö & $\mathbf{N}$ & ö & $\mathbf{N}$ & ö & $\mathbf{N}$ & ö & $\mathbf{N}$ & & \\
\hline 1 & 1,00 & 1 & 1,00 & 1 & 1,00 & 7 & 1,00 & 0,00 & 1 \\
\hline 17 & 0,68 & 77 & 0,58 & 70 & 0,01 & 9 & 0,05 & 67,03 & 3 \\
\hline 29 & 0,44 & 11 & 0,94 & 35 & 0,51 & 8 & 0,52 & 39,45 & 2 \\
\hline 13 & 0,76 & 8 & 0,96 & 25 & 0,66 & 8,4 & 0,33 & 32,21 & 2 \\
\hline 8 & 0,86 & 22 & 0,88 & 45 & 0,37 & 6 & 0,09 & 44,87 & 2 \\
\hline 1 & 1,00 & 121 & 0,33 & 8 & 0,90 & 6,3 & 0,36 & 35,09 & 2 \\
\hline 45 & 0,12 & 139 & 0,23 & 62 & 0,13 & 8,9 & 0,10 & 85,60 & 4 \\
\hline 10 & 0,82 & 83 & 0,54 & 4 & 0,96 & 7,9 & 0,57 & 27,68 & 2 \\
\hline 2 & 0,98 & 49 & 0,73 & 66 & 0,07 & 8,7 & 0,19 & 50,64 & 3 \\
\hline 36 & 0,30 & 137 & 0,24 & 6 & 0,93 & 7,9 & 0,57 & 48,90 & 2 \\
\hline 45 & 0,12 & 128 & 0,29 & 35 & 0,51 & 8,4 & 0,33 & 68,47 & 3 \\
\hline 34 & 0,34 & 8 & 0,96 & 70 & 0,01 & 7,5 & 0,76 & 48,09 & 2 \\
\hline 50 & 0,02 & 42 & 0,77 & 63 & 0,11 & 8,5 & 0,29 & 70,21 & 3 \\
\hline 4 & 0,94 & 16 & 0,92 & 15 & 0,80 & 7,1 & 0,95 & 9,78 & 1 \\
\hline 7,7 & 0,67 & 60 & 0,16 & 21 & 0,89 & 6,6 & 0,64 & 41,29 & 2 \\
\hline 20 & 0,62 & 17 & 0,91 & 1 & 1,00 & 7,2 & 0,90 & 14,10 & 1 \\
\hline 46 & 0,10 & 124 & 0,32 & 69 & 0,03 & 8,5 & 0,29 & 81,76 & 4 \\
\hline 48 & 0,06 & 116 & 0,36 & 7 & 0,91 & 9 & 0,05 & 65,43 & 3 \\
\hline 24 & 0,54 & 32 & 0,83 & 27 & 0,63 & 6,2 & 0,27 & 43,28 & 2 \\
\hline 49 & 0,04 & 176 & 0,03 & 47 & 0,34 & 8,9 & 0,10 & 87,38 & 4 \\
\hline 3 & 0,96 & 20 & 0,89 & 11 & 0,86 & 6,7 & 0,73 & 14,03 & 1 \\
\hline 49 & 0,04 & 1 & 1,00 & 31 & 0,57 & 6,1 & 0,18 & 55,18 & 3 \\
\hline 11 & 0,80 & 9 & 0,96 & 22 & 0,70 & 8,6 & 0,24 & 32,66 & 2 \\
\hline 40 & 0,22 & 128 & 0,29 & 29 & 0,60 & 7,3 & 0,86 & 50,73 & 3 \\
\hline 16 & 0,70 & 10 & 0,95 & 24 & 0,67 & 7 & 1,00 & 16,97 & 1 \\
\hline 43 & 0,16 & 96 & 0,47 & 15 & 0,80 & 8,7 & 0,19 & 59,44 & 3 \\
\hline 5 & 0,92 & 8 & 0,96 & 16 & 0,79 & 7,5 & 0,76 & 14,29 & 1 \\
\hline 35 & 0,32 & 164 & 0,09 & 67 & 0,06 & 8,6 & 0,24 & 82,29 & 4 \\
\hline 31 & 0,40 & 5 & 0,98 & 64 & 0,10 & 7,7 & 0,67 & 46,41 & 2 \\
\hline 9 & 0,84 & 101 & 0,44 & 9 & 0,89 & 8,3 & 0,38 & 36,23 & 2 \\
\hline 24 & 0,54 & 126 & 0,30 & 70 & 0,01 & 7 & 1,00 & 53,54 & 3 \\
\hline 15 & 0,72 & 23 & 0,88 & 1 & 1,00 & 7,1 & 0,95 & 11,25 & 1 \\
\hline 49 & 0,04 & 169 & 0,07 & 59 & 0,17 & 6,2 & 0,27 & 86,27 & 4 \\
\hline 19 & 0,64 & 26 & 0,86 & 7 & 0,91 & 7,6 & 0,71 & 21,76 & 1 \\
\hline 5 & 0,92 & 52 & 0,72 & 8 & 0,90 & 7 & 1,00 & 11,59 & 1 \\
\hline 14 & 0,74 & 7 & 0,97 & 5 & 0,94 & 6,8 & 0,82 & 13,31 & 1 \\
\hline 48 & 0,06 & 130 & 0,28 & 61 & 0,14 & 8,4 & 0,33 & 79,54 & 4 \\
\hline 20 & 0,62 & 128 & 0,29 & 27 & 0,63 & 8,5 & 0,29 & 54,30 & 3 \\
\hline 1 & 1,00 & 101 & 0,44 & 28 & 0,61 & 8,6 & 0,24 & 42,59 & 2 \\
\hline 18 & 0,66 & 177 & 0,02 & 30 & 0,59 & 9 & 0,05 & 67,13 & 3 \\
\hline 16 & 0,70 & 106 & 0,42 & 43 & 0,40 & 7 & 1,00 & 37,11 & 2 \\
\hline 38 & 0,26 & 67 & 0,63 & 44 & 0,39 & 7,3 & 0,86 & 46,62 & 2 \\
\hline 21 & 0,60 & 113 & 0,38 & 57 & 0,20 & 7,4 & 0,81 & 50,35 & 3 \\
\hline 40 & 0,22 & 35 & 0,81 & 47 & 0,34 & 8,3 & 0,38 & 56,14 & 3 \\
\hline 18 & 0,66 & 17 & 0,91 & 32 & 0,56 & 6,2 & 0,27 & 39,99 & 2 \\
\hline 38 & 0,26 & 18 & 0,91 & 53 & 0,26 & 8,8 & 0,14 & 60,87 & 3 \\
\hline 46 & 0,10 & 124 & 0,32 & 3 & 0,97 & 8,9 & 0,10 & 62,92 & 3 \\
\hline 39 & 0,24 & 165 & 0,09 & 39 & 0,46 & 7 & 1,00 & 55,38 & 3 \\
\hline 15 & 0,72 & 137 & 0,24 & 15 & 0,80 & 9 & 0,05 & 54,71 & 3 \\
\hline 47 & 0,08 & 85 & 0,53 & 33 & 0,54 & 8,6 & 0,24 & 65,16 & 3 \\
\hline
\end{tabular}

Ö=Ölçülen değer, N=Normalize değer, K.Y.=Kirlilik yüzdesi, MS=Matematiksel Sınıfi

Tablo 7 BOİ $_{5}$ KOİ, AKM ve pH parametrelerine ait ölçülen değer, karşıllk gelen normalize değer, kirlilik yüzdesi ve kirlilik yüzdesine karşıllk gelen 
matematiksel sınıflandırma değerini göstermektedir. Burada 50 adet farklı numune sonucuna ait değer yer almaktadır.

\section{Araştırma Bulguları}

\subsection{Deneysel Sonuçlar}

AÖM ile eğitim ve test verileri kullanılarak yapılan sınıflandırma için hardlimit, sine ve sigmoidal adlı üç farklı aktivasyon fonksiyonu kullanılmıștır. Bu aktivasyon kodlarının test süreleri ve test doğruluk oranları karşılaştırılmıştır. Bu değerler Tablo 8'de verilmiştir. Yapılan bu ilk karşılaştırma aşamasında kullanılan gizli nöron sayısı 50'dir. Eğitim verisi 50 satırdan oluştuğu için en fazla 50 nöron kullanılabilmiştir. AÖM çalışması için Matlab yazılımı kullanılmıştır. AÖM'nde çıkış ağırlıkları analitik olarak hesaplanırken, giriş ağırlıklarının rastgele hesaplanmasından dolayı sonuçlar programın her çalıștırılmasında birbirine yakın ama farklı değerlerde çıkmaktadır. Bu sebeple buradaki "Test Süresi” ve "Test Doğruluğu" değerleri aynı nöron sayısında programın 3 kez çalıştırılması sonucunda elde edilen ortalama değerlerdir. Eğitim veriler 0-1 arasında normalize edilmiş değerlerden oluşmaktadır.

Tablo 8. AÖM aktivasyon fonksiyonlarına göre test doğruluğu oranları (50 nöron sayısında)

\begin{tabular}{|c|c|c|}
\hline $\begin{array}{c}\text { Aktivasyon } \\
\text { Fonksiyonu }\end{array}$ & $\begin{array}{c}\text { Test Süresi } \\
\text { (sn.) }\end{array}$ & $\begin{array}{c}\text { Test } \\
\text { Doğruluğu } \\
\text { (\%) }\end{array}$ \\
\hline Sig & 0,00056 & 30,00 \\
\hline Sin & 0,00051 & 50,00 \\
\hline Hardlim & 0,00040 & 60,00 \\
\hline
\end{tabular}

AÖM aktivasyon fonksiyonlarına göre test doğruluğu oranlarlarına bakıldığında en yüksek değerin hardlimit fonksiyonu tarafindan \% 60,00 test doğruluğu oranı ve 0,00040 saniyelik test süresi ile karşılandığı görülmektedir. Ancak farklı nöron sayılarında diğer fonksiyonlarında ne şekilde tepki vereceğini incelemek amacı ile bu 3 aktivasyon fonksiyonunun 6 farklı nöron sayısına bağlılığı incelenmiștir. Yapılan çalışma sonrasında Tablo 9'daki değerler elde edilmiștir.

Tablo 9. Farklı aktivasyon kodu ve nöron sayılarına göre test süreleri ve test doğruluğu oranları

\begin{tabular}{|c|c|c|c|c|c|}
\hline $\begin{array}{c}\text { Aktivasyon } \\
\text { kodu ve } \\
\text { Gizli nöron } \\
\text { sayısı }\end{array}$ & $\begin{array}{c}\text { Test } \\
\text { Süresi } \\
\text { (sn.) }\end{array}$ & $\begin{array}{c}\text { Test } \\
\text { Doğruluğ } \\
\mathbf{u} \\
\mathbf{( \% )}\end{array}$ & $\begin{array}{c}\text { Aktivasyon } \\
\text { kodu ve } \\
\text { Gizli nöron } \\
\text { sayısı }\end{array}$ & $\begin{array}{c}\text { Test } \\
\text { Süresi } \\
\text { (sn.) }\end{array}$ & $\begin{array}{c}\text { Test } \\
\text { Doğruluğ } \\
\mathbf{u} \text { (\%) }\end{array}$ \\
\hline Sig-5 & 0,00030 & 60 & Sig-30 & 0,00031 & 60 \\
\hline Sin-5 & 0,00052 & 60 & Sin-30 & 0,00035 & 70 \\
\hline Hardlim-5 & 0,00037 & 40 & Hardlim-30 & 0,00048 & 60 \\
\hline Sig-10 & 0,00053 & 40 & Sig-40 & $\mathbf{0 , 0 0 0 3 7}$ & $\mathbf{8 0}$ \\
\hline Sin-10 & $\mathbf{0 , 0 0 0 3 4}$ & $\mathbf{8 0}$ & Sin-40 & 0,00054 & 50 \\
\hline Hardlim-10 & 0,00040 & 50 & Hardlim-40 & 0,00037 & 60 \\
\hline Sig-20 & $\mathbf{0 , 0 0 0 5 2}$ & $\mathbf{8 0}$ & Sig-50 & 0,00056 & 30 \\
\hline Sin-20 & 0,00031 & 70 & Sin-50 & 0,00051 & 50 \\
\hline Hardlim-20 & 0,0004 & 50 & Hardlim-50 & 0,0004 & 60 \\
\hline
\end{tabular}

En yüksek test doğruluğu oranlarının \% 80 ile sin-10, sig-20 ve sig-40 aktivasyon fonksiyonu ve nöron sayılarında gerçekleșmiștir. Bunlardan en düşük test süresine sahip olan ise sin-10 aktivasyon fonksiyonudur.

$\mathrm{Bu}$ sonuca göre sin-10 aktivasyon fonksiyonu kullanılarak 10 satırdan olușan test verisi üzerine çalışma yapılmıştır. AÖM algoritmasının çalıştırılması sonucunda elde edilen sınıflandırma sonuçları Tablo 10'daki gibi olmuştur. Tablo 10 AÖM sınıflandırma değerlerinin yanı sıra BOİ 5 , KOİ, AKM ve pH parametrelerine ait gerçek sonuçları ve karşılık gelen normalize değerleri, kirlilik yüzdesi ve matematiksel sınıflandırma değerlerini de içermektedir.

Tablo 10. Test verilerine ait BOİ, KOİ, AKM, pH değerleri, bu değerlere karşılık gelen matematiksel ve AÖM sınıfı değerleri

\begin{tabular}{|c|c|c|c|c|c|c|c|c|c|c|}
\hline \multicolumn{2}{|c|}{ вої } & \multicolumn{2}{|c|}{ кої } & \multicolumn{2}{|c|}{ AKM } & \multicolumn{2}{|c|}{ pH } & \multirow{2}{*}{$\begin{array}{l}\text { K.Y. } \\
(\%)\end{array}$} & \multirow{2}{*}{ MS } & \multirow{2}{*}{ AS } \\
\hline ö & $\mathrm{N}$ & ö & $\mathbf{N}$ & ö & $\mathrm{N}$ & $\ddot{0}$ & $\mathrm{~N}$ & & & \\
\hline 9 & 0,84 & 3 & 0,99 & 16 & 0,79 & 7,3 & 0,86 & 13,21 & 1 & 1 \\
\hline 49 & 0,04 & 139 & 0,23 & 65 & 0,08 & 6,9 & 0,91 & 68,33 & 3 & 3 \\
\hline 20 & 0,62 & 57 & 0,69 & 40 & 0,44 & 7,4 & 0,81 & 35,99 & 2 & 2 \\
\hline 26 & 0,50 & 178 & 0,02 & 7 & 0,91 & 9 & 0,05 & 63,05 & 3 & 3 \\
\hline 3 & 0,96 & 106 & 0,42 & 68 & 0,04 & 6,6 & 0,64 & 48,64 & 2 & 3 \\
\hline 44 & 0,14 & 143 & 0,21 & 67 & 0,06 & 8,5 & 0,29 & 82,68 & 4 & 4 \\
\hline 7 & 0,88 & 5 & 0,98 & 2 & 0,99 & 8,1 & 0,48 & 17,00 & 1 & 1 \\
\hline 12 & 0,78 & 85 & 0,53 & 38 & 0,47 & 8,3 & 0,38 & 45,87 & 2 & 2 \\
\hline 40 & 0,22 & 12 & 0,94 & 17 & 0,77 & 7,2 & 0,90 & 29,13 & 2 & 1 \\
\hline 50 & 0,02 & 159 & 0,12 & 69 & 0,03 & 8 & 0,52 & 81,17 & 4 & 4 \\
\hline
\end{tabular}
MS=Matematiksel Sınıfı, AS=AÖM Sınıf

Elli farklı satırdan oluşan eğitim verisinin kirlilik yüzdesi denklem 8 kullanılarak elde edilmiş ve matematiksel sınıflandırması yapılmıștır. Tablo 10 'dan da görüleceği üzere 10 adet BOİ5, KOİ, AKM ve pH değerine ait test sonuçlarının kirlilik yüzdesi ve matematiksel sınıflandırma işlemi de aynı şekilde gerçekleştirilmiştir. $\mathrm{Bu} 10$ satırdan oluşan test sonuçlarının AÖM ile sınıflandırılması da yine AÖM algoritması ile elde edilmiş olup, üretilen sonuçlar Tablo 10'da gösterildiği gibi olmuştur. Buna göre, Tablo 10'daki matematiksel sinıflandırma ve AÖM sınıflandırması değerleri karşılaștırıldığında 10 sınıflandırma işleminin 8 tanesi AÖM tarafından doğru sinıflandırılmıştır. Sadece 2 adet sonucun sinıflandırılması yanlış yapılmıştır. Yanlış tahmin edilen değerlere bakıldığında \% 48,64'lük sonuç 2 . kirlilik sınıfı yerine 3. kirlilik sınıfına yerleștirilmiștir. Diğer yanlış tahminde ise \% 29,13'lük sonuç 2 . kirlilik sınıfı yerine 1 . kirlilik sınıfina yerleştirilmiştir. Bu durumun hatalı olan her iki yüzdelik sonuç değerin kendi kirlilik sınıflarının sınır değerlerine yakın olmasından ve buna bağlı olarak AÖM'nin bunu kestirememesinden kaynaklandığı düşünülmektedir. 


\section{Sonuç ve Tartışma}

Bu çalışmada, BOİं, KOİ, AKM ve pH parametreleri çerçevesinde evsel atıksu numunelerinin temizlik derecesini belirlemek üzere bir tahmin çalışması yapılmıştır. SKKY Tablo 21.1'deki sınır değerler dikkate alınmıştır. Tahmin için AÖM algoritması kullanılmıştır. En düşük sayısal değerli sonucun \% 0 kirli, en yüksek sayısal değerli sonucun ise \% 100 kirli olduğu varsayılarak 4 farklı yüzdelik dilim elde edilmiștir. Yüzdelik dilimler ise dört sınıfı temsil etmiştir. 1. sınıf çok temiz suyu ifade ederken, 4. sınıf az temiz suyu ifade etmiştir. Bu doğrultuda, AÖM ile sınıflandırma çalışması için birbirinden farklı 50 adet normal ölçüm sonucuna karşılık gelen normalize ve matematiksel sınıflandırma değerleri elde edilmiştir. Normalize değerler AÖM'nin eğitimi için giriş verisi olarak, matematiksel sınıflandırma değerleri ise çıkış verisi olarak kullanılmıştır. Buna karşılık bu parametreler için rastgele seçilen ve sınır değerler arasında olan 10 adet sonuca karşıllk gelen normalize değerler ise AÖM'nin test işleminde giriş verisi olarak kullanılmıştır.

AÖM aktivasyon fonksiyonlarına göre test doğruluğu oranlarına bakıldığında en yüksek değerin hardlimit fonksiyonu tarafindan \% 60,00 test doğruluğu oranı ve 0,00040 saniyelik test süresi ile karşılandığı görülmektedir. Ancak farklı nöron sayılarında diğer fonksiyonlarında ne şekilde tepki vereceğini incelemek amacı ile bu 3 aktivasyon fonksiyonunun 6 farklı nöron sayısına bağlılığı incelenmiştir. En yüksek test doğruluğu oranları \% 80 test doğruluğu oranları ile sin-10, sig- 20 ve sig- 40 aktivasyon fonksiyonu ve nöron sayllarında elde edilmiștir. En düșük test süresine sahip olan ise sin-10 aktivasyon fonksiyonu olduğu görülmüştür.

Bu doğrultuda ölçülen 10 adet BOİ5, KOİ, AKM ve pH parametre sonuç değerleri ve bu sonuç değerlerine karşılık gelen matematiksel sınıflandırma değerleri ile AÖM tarafından tahmini yapılan sine-10 aktivasyon koduna ait sınıflandırma değerleri karşılaştırılmıştır. 10 sonuçtan 8 tanesi AÖM tarafından doğru sınıflandırılmıştır. Sadece 2 adet sonucun sınıflandırılması yanlış yapılmıştır. Yanlış tahminler \% 48,64'lük sonucun 2. kirlilik sinıfı yerine 3 . kirlilik sınıfına yerleştirilmesi ve \% 29,13'lük sonucun 2 . kirlilik sinıfı yerine 1. kirlilik sınıfına yerleştirilmesidir. $\mathrm{Bu}$ durumun hatalı olan her iki yüzdelik sonuç değerinin kendi kirlilik sınıflarının sınır değerlerine yakın olmasından kaynaklandığı düşünülmektedir. İlk yanlış sonuçta tahmin edilen \% 48,64 kirlilik oranının \% 44,99 sınır değerine, ikinci yanlış sonuçta ise tahmin edilen \% 29,13 kirlilik oranının \%24,99 sınır değerine yakın olduğu görülmektedir. Bu yakınlıktan dolayı AÖM'nin doğru sınıflandırmayı yapamadı̆̆ı düșünülmektedir.

Ülkemizde evsel atıksu arıtma tesislerinde ayda iki defa 2 saatlik kompozit numune alımı gerçekleştirilmektedir. Alınan numunelere ait sonuçların $\mathrm{BOI}_{5}$, KOİ ve AKM için 1, pH için ise 7 çıkması istenmektedir. Ancak, uygulamada elde edilen sonuçlar incelendiğinde BOİ 5 için 50, KOİ için 180, AKM için 70 ve pH için ise 6-9 olan üst sınırlarda çıkan sonuçlar bile temiz kabul edilirken, hemen bir sonraki değerler kirli olarak kabul edilmektedir. Bundan dolayı atıksu arıtma tesislerinden çıkan ve temiz kabul edilen her atıksu aynı temizliğe sahip değildir. Bu çalışmadaki AÖM sınıflandırmasının kullanılması durumunda herhangi bir ayrı analiz yöntemine gerek kalmadan akredite laboratuvar tarafından ölçülmüș dört parametre üzerinden temizlilik yüzdesi hesaplanabilecektir.

\section{Conflict of Interest / Çıkar Çatışması}

Yazarlar tarafından herhangi bir çıkar çatışması beyan edilmemiștir.

No conflict of interest was declared by the authors.

\section{Kaynaklar}

Baran, B., 2017. Yenilenebilir Enerji Kaynaklarını İçeren Mikro-şebeke Sistemlerin Akıllı Yönetimi, Doktora Tezi, İnönü Üniversitesi, Türkiye.

Bingül, Z., Altıkat, A., 2017. Evsel Nitelikli Atıksu Arıtma Tesisi Çıkış Sularının Tarımsal Sulamada Kullanılabilirliği. Iğdır Univ. J. Inst. Sci. \&Tech. 7(4): 69-75.

Çatak, F.Ö.,2015. Rassal Bölümlenmiş Veri Üzerinde Aşırı Öğrenme Makinesi ve Topluluk Algoritmaları ile Sınıflandırma, 2015 IEEE 23. Sinyal İşleme ve İletişim Uygulamaları Kurultayı(SIU), 16-19.

Erdoğan, O.A., Zengin, G.E., 2005. Türkiye'de evsel atıksu oluşum miktarları ve karakterizasyonu. itüdergisi/e-Su Kirlenmesi Kontrolü Cilt:15, Sayı:1-3, 57-69.

Granata, F., Papirio, S., Esposito, G., Gargano, R., Marinis, G.d. 2017, Machine Learning Algorithms for the Forecasting of Wastewater Quality Indicators. Water 9(2), 105.

Hamed, M.M., Khalafallah, M.G., Hassanien, E.A., 2004. Prediction of wastewater treatment plant performance using artificial neural networks. Environmental Modelling\& Software. 19 (10): 919928.

Huang, G.B., Zhu, Q.Y., Siew, C.K., 2006. Extreme Learning Machine: Theoryand Applications. Neurocomputing. 70: 489-501.

Rene, E R., Saidutta, M. B., 2008. Prediction of Water Quality Indices by Regression Analysis and Artificial Neural Networks. Int. J. Environ. 2(2): 183-188.

Sinan, R.K., 2010. Evsel Atıksu Arıtma Tesislerinde Ön Arıtım ve Biyolojik Arıtım Çıkış Parametrelerinin 
YSA İle Tahmini. Yüksek Lisans Tezi. Selçuk Üniversitesi, Türkiye.

SKKY, 2004. Su Kirliliği Kontrolü Yönetmeliği.

Tanyol, M., Uslu, G., 2013. Tunceli Evsel Atıksu Arıtma Tesisinin Arıtma Etkinliğinin Değerlendirilmesi. Mehmet Akif Ersoy Üniversitesi Fen Bilimleri Enstitüsü Dergisi 4 (2): 24-29. 